Huesmann, L. R., Dubow, E. F., Eron, L. D., \& Boxer, P. (2006) Middle childhood family-contextual and personal factors as

4 predictors of adult outcomes. In A. C. Huston \& M. N. Ripke (Eds.)

Developmental Contexts in Middle Childhood: Bridges to Adolescence

and Adulthood (pp. 62-86). Cambridge, UK: Cambridge University Press.

\title{
Middle Childhood Family-Contextual and Personal Factors as Predictors of Adult Outcomes
}

\section{Rowell Huesmann, Eric F. Dubow, Leonard D. Eron, and Paul Boxer}

Early models of behavior development tended to de-emphasize the importance of the middle childhood years, labeling this time period a "latency" phase between the theoretically more active periods of early childhood and adolescence (Freud, 1923/1961). As more recent models attest, middle childhood actually is a period critical for the development of important psychosocial functions such as cognitive skill acquisition (e.g., Piaget, 1965), social relationship formation (e.g., McHale, Dariotis, \& Kauh, 2003), and self-concept consolidation (e.g., Jacobs, Bleeker, \& Constantino, 2003). Contemporary social cognitive theories consider middle childhood a critical time for the development of social scripts, normative beliefs, and world schemas that influence behavior throughout life (Huesmann, 1998; Huesmann \& Guerra, 1997). Behaviors established in middle childhood have been shown to display substantial continuity into adulthood (e.g., aggression: Huesmann, Eron, Lefkowtiz, \& Walder, 1984; academic achievement: Jimerson, Egeland, Sroufe, \& Carlson, 2000). A key concern therefore is identifying which factors exert important influences on children during middle childhood and what adult outcomes are affected by those factors.

In this chapter, we present findings from the Columbia County Longitudinal Study (CCLS), a long-term prospective study that began in 1960 with the entire third grade population of Columbia County, New York. In the most recent wave of data collection, we resampled those individuals at approximately 48 years of age. Our primary concern in this chapter is the degree to which family-contextual and child-personal factors during middle childhood predict three important domains of adult behavioral outcomes: aggressive behavior, intellectual/educational achievement, and occupational success. We also examine the moderating effects of gender on the prediction of adult outcomes.

\section{FAMILY-CONTEXTUAL INFLUENCES DURING MIDDLE CHILDHOOD}

Families are embedded in the broader social-economic context of the community. Leventhal and Brooks-Gunn (2000) suggested that communities characterized by socioeconomic disadvantage have relatively few institutional resources to support children's development. Those authors noted that, for example, school achievement should be influenced by the availability and use of libraries, museums, and literacy programs; social competence should be influenced by the availability and use of parks, sports programs, and youth groups, assuming that the program participants and facilitators are appropriate role models. Further, socioeconomic disadvantage is associated with crime and violence in the community that provides children with normative models of antisocial behavior. Tolan, Gorman-Smith, and Henry (2003) found that a composite score representing community-structural characteristics (i.e., concentrated neighborhood poverty, ethnic heterogeneity, economic investment, neighborhood violent crime) played an etiological role in adolescent gang membership and violence.

At the level of interactions within the family, it is well established in social learning models (e.g., Huesmann, 1998) that parents exert substantial influence on their children's behavior. For example, children exposed to more rejecting and aggressive parenting contexts, as well as interparental conflict, display greater aggression (Cummings \& Davies, 1994; Eron, Walder, \& Lefkowitz, 1971; Huesmann et al., 1984; Lefkowitz, Eron, Walder, \& Huesmann, 1977; Patterson, 1982). Presumably, children learn aggressive problem-solving styles as a result of repeated exposure to such models.

\section{INDIVIDUAL/PERSONAL INFLUENCES DURING} MIDDLE CHILDHOOD

Negotiating academic demands and peer relationships are among the most important tasks of middle childhood (e.g., Erikson, 1963). Individ$\mathrm{ual}$ / personal attributes such as intellectual ability, social competence (e.g., popularity), and behavior regulation (e.g., aggressiveness) contribute to the child's success at those tasks. These attributes are somewhat stable over time (e.g., Coie \& Dodge, 1983; Huesmann et al., 1984). For example, Coie and Dodge (1983) found that $42 \%$ of fifth graders identified as "rejected" remained rejected by ninth grade, and $29 \%$ of fifth graders identified as "popular" remained so in ninth grade. Using data from the CCLS, Huesmann (2001) reported that $36 \%$ of third graders classified as high (upper quartile) in aggression remained in this position through adolescence and adulthood, and $37 \%$ of third graders classified as low (lower 
quartile) in aggression remained in this position through adolescence and adulthood.

Despite the moderate stability from middle childhood onward in these attributes, the results are consistent with instability as well. Thus, it is important to consider also the extent to which contextual factors uniquely account for later outcomes of these middle childhood attributes (Phelps, Furstenberg, \& Colby, 2002; Pulkkinen \& Caspi, 2002). For example, Kokko and Pulkkinen (2000) found that individuals who displayed higher levels of aggression during middle childhood were more likely than others to enter a "cycle of maladaptation" involving poorer educational outcomes and greater unemployment. However, such individuals fared better if they experienced supportive family contexts during middle childhood (as indicated by retrospective reports), and if they exhibited higher levels of prosocial behavior during that time period (Pulkkinen, Nygren, \& Kokko, 2002).

\section{THE ROLE OF GENDER}

Gender is probably the most extensively examined individual/personal variable in any study of development. For many years, we have explored gender differences in aggressive behavior, and how those differences can be explained on the basis of differential socialization of boys and girls (Eron et al., 1971; Huesmann, 2001, Lefkowitz, Eron, Walder, \& Huesmann, 1973). We also have noted the recent reduction in this difference and have ascribed it to changes over the years in the socialization of the two sexes (Eron \& Huesmann, 1989). Important gender differences also have been identified for educational achievement and occupational attainment (Eccles, 1994). Thus, one goal of the current investigation is to examine whether there are gender differences in the relations of our criterion variables of interest in middle childhood to outcomes in middle adulthood.

In this chapter, based on data from the Columbia County Longitudinal Study, we examine how well we can predict three psychosocial outcomes of interest over a 40-year span from middle childhood (age 8 ) to middle adulthood (age 48 ). The three adult outcomes are aggression (physical aggression, aggressive personality, spousal abuse, physical punishment), intellectual/educational achievement (verbal and arithmetic skill, years of education, self-perceptions of cognitive competence), and occupational prestige. Using structural equations and path modeling, we evaluate whether those outcomes are better predicted by their behavioral predecessors (e.g., early aggression to later aggression) or by the middle childhood contextual influences of family SES and family interaction variables. We also consider whether the prediction of adult outcomes varies by gender.

\section{METHOD}

\section{Design of the Columbia County Longitudinal Study}

The CCLS began in 1960 and has so far culminated in the collection of four waves of data over a 40 -year span on children who were living in Columbia County, $N Y$, in 1960 . The entire population of third graders $(N=$ $856 ; 436$ boys, 420 girls) in Columbia County, a semirural area of New York State, participated in the first phase of this project in 1960 (Eron et al., 1971). We denote them as generation G2 and their parents as generation Gi. The dominant issues in selecting the sample were cost, geographic proximity, availability, representativeness, and low mobility. At that time, $85 \%$ of the participants' mothers and $71 \%$ of their fathers were also interviewed. Follow-up assessments of G2 were conducted in both $1970(n=$ $427)$ and $1981(n=409)$; in 1981 we also were able to obtain data on 76 children of the original subjects (i.e., $G_{3}$ ). We do not present findings from the 1970 and 1981 assessments in this chapter; the interested reader is directed to Lefkowitz et al. (1977; 1970 follow-up) or Huesmann et al. $(1984 ; 1981$ follow-up) for more information.

In our most recent wave of data collection (Huesmann et al., 2002), between 1999 and 2002, we reinterviewed 284 of the G2 participants in person and another 239 by mail/telephone, for a total of 523 (268 males, 255 females). By also obtaining archival data from the New York State Divisions of Criminal Justice and Motor Vehicles, we obtained follow-up data on 683 of the original G2 participants. We obtained interviews from "second persons" who knew the participants very well (mostly spouses) for 394 participants. We collected some data on 705 of these participants' $\mathrm{G}_{3}$ children, and completed interviews with $551 \mathrm{G}_{3}$ children (ages 4 years old and older). We attempted to interview up to two children per family generally the oldest and youngest. We interviewed at least one child for $82 \%$ of our reinterviewed participants who had at least one child. The mean age of the interviewed children was 19.97 years $(S D=5.77)$.

Analyses for this chapter are based on data collected about $\mathrm{G}_{2}$, the original participants, during Waves $x$ (age 8 ) and 4 (age 48 ). We also draw on data provided about the original participants by their parents (G1) in 1960 and by their children $\left(G_{3}\right)$ and spouses in 1999-2002.

\section{Description of Sample in Waves $x$ and 4}

Columbia County, NY, is semirural with a few heavy industries. Of its approximately 63,000 current residents, about 11,000 live in the largest city and county seat, Hudson. The county has had a depressed economy for the last 50 years, although it has begun to benefit from the encroachment of the New York City metropolitan area. At the time the study was 
started, there were 38 public and private third-grade classrooms in the county, all of which were included in the sample. Over $90 \%$ of the original sample of 856 participants were Caucasian; $51 \%$ were male and $49 \%$ were female. The number of ethnic minorities (i.e., $3 \%$ African American, $<1 \%$ Asian or Pacific Islanders, $<1 \%$ Hispanic) was too small to allow separate analyses. The participants came from a broad range of socioeconomic backgrounds (mean of 4.3 on Warner's scale of fathers' occupational status, i.e., middle class; Warner, Meeker, \& Eells, 1960) and displayed a wide range of intelligence (mean IQ of $104, S D=14$ ).

For the 523 participants reinterviewed during 1999-2002, the mean age was 48.85 years old $(S D=.81)$; the average education level was between some college and a college degree; the average occupational attainment reflected middle class status (the average occupational prestige code using Stevens \& Hoisington's [1987] prestige scores reflected jobs such as sales, bookkeepers, secretaries); and $69 \%$ of the original participants were living with their spouses.

Differences Between the Original Sample and the 1999-2002 Resample. In the 4o-year follow-up, we collected some data on $80 \%$ (683) of our original participants, and interviewed $61 \%(523)$ of them extensively. The number of relocated participants who refused to be interviewed (despite substantial financial incentives) was higher than expected $(n=144)$, but the completed reinterview rate of $61 \%$ over 40 years still provides us with a substantial sample for analysis. However, we must ask whether attrition introduced bias into the sample. In most longitudinal studies, more aggressive and antisocial participants, and those of lower socioeconomic status, are somewhat less likely to be resampled. We found that the reinterviewed participants had lower levels of age- 8 aggression compared to those who were not reinterviewed at Wave 4. Nevertheless, the plots of the distributions reveal that many of the high aggressive participants were resampled and there was no substantial reduction of range that might have made it hard to detect relations between aggression and other variables. There was no significant difference in 1960 father's occupational level between reinterviewed participants and dropouts, but reinterviewed participants' parents in 1960 had higher levels of education and value of housing. There was no significant difference between reinterviewed participants and dropouts in an index of negative family interaction processes.

\section{Procedures in Waves 1 and 4}

The methods of data collection across the first three waves of the Columbia County Longitudinal Study have been reported elsewhere (e.g., Eron et al., 1971; Lefkowitz et al., 1977; Huesmann et al., 2002; Huesmann et al., 1984).
In Wave 1 in 1960, two main sources of data were used: classroom-based peer nominations and extensive individual parent interviews.

For the 40-year follow-up, interviews were conducted by computer in a field office and by mail/telephone for those participants who could not come to the office. ${ }^{1}$ Interviews in the field office were up to four hours in duration for original participants, three hours for their secondpersons/spouses, and two hours for their children. Original participants were paid $\$ 100$, second-persons / spouses were paid $\$ 75$, and children were paid $\$ 50$ for their participation.

\section{Measures}

Our analyses for the present chapter focus on the effects of familycontextual and individual/personal factors during middle childhood (age 8) on adult outcomes 40 years later.

Family-Contextual Factors During Middle Childhood. We examined two domains of family-contextual factors: family background (SES) and negative family interaction. For these variables, if two parents were interviewed, their scores were averaged.

FAMILY BACKGROUND (SES) VARIABLES. (a) Father's occupational level (Warner et al., 1960) ranges from $1=$ laborer to $7=$ professional; (b) Parents' educational level (Eron et al., 1971) reflects the parents' levels of educational attainment, ranging from $1=$ under 7 years to $7=$ graduate $/$ professional training; (c) Value of family housing (Eron et al., 1971) ranges from 1 = inexpensive rental to $4=$ expensive owned.

NEGATIVE FAMILY INTERACTION. Negative family interaction (see Eron et al., 1971) was measured by three indicators: (a) Parental rejection is the sum of scores on 10 items about how "unsatisfied" the parent is with the child; for example, "Are you satisfied with your child's manners? Does your child read as well as he/she should?" (yes/no) $(\alpha=.75)$. (b) Parents' endorsement of hitting the child as a form of punishment was the sum of parents' endorsement of physical punishment in response to two vignettes depicting child transgressions; for example, "If your child was rude to you, would you. ..." For each of these two vignettes, one physical punishment

I There were mean differences by interview type for four adult outcome variables. Compared to participants interviewed in person, those interviewed by mail/phone had higher levels of education and occupational status, and lower levels of self-reported severe physical aggression and spouse-reported partner aggression. However, a series of hierarchical regressions showed no evidence that interview type moderated the relations of the middle childhood personal or contextual factors with the adult outcomes. The obtained differences are not surprising given that geographic mobility is highly related to SES. Personal interviews were obtained almost exclusively from participants who still lived in or near Columbia County, 
was included: "spank your child until he/she cries?" or "slap your child in the face?" (yes/no). Thirty-five percent of the fathers and $36 \%$ of the mothers endorsed at least one of the two physical punishment items. (c) Parental disharmony measures the amount and seriousness of disputes between the parents. It is the sum of 10 items of the form; for example, "Do you or your spouse ever leave the house during an argument?" and "Do arguments between you and your spouse ever settle anything?" (yes/no) $(\alpha=.77)$.

Individual/Personal Variables During Middle Childhood. We included three individual/personal variables that were assessed when the child was 8 years of age.

CHILd's PEer-Nominated AGgression. Eron et al. (1971) defined aggression as "an act whose goal response is injury to another object" (p. 30). Their 10 aggression items cover physical (e.g., "Who pushes and shoves other children?"), verbal (e.g., "Who says mean things?"), acquisitive (e.g., "Who takes other children's things without asking?"), and indirect (e.g., "Who makes up stories and lies to get other children into trouble?") aggressive acts. The score represents the proportion of times the child was nominated by classmates on any of 10 items. This measure is described in detail elsewhere (Eron et al., 1971; Huesmann et al., 1984), has been widely used, and has an $\alpha=.90$ in cross-national samples (Huesmann \& Eron, 1986).

CHILD'S PEER-NOMINATED POPULARITY. This score represents the proportion of times the participant was nominated by his or her classmates on two popularity items; for example, "Who would you like to have as a best friend?" $(\alpha=.87)$ (Eron et al., 1971).

CHILD's IQ. The child's IQ was assessed with the California Short-Form Test of Mental Maturity (Sullivan, Clark, \& Tiegs, 1957). Kuder-Richardson reliability coefficients range from $.87-.89$ across grades; the total score correlates approximately .75 with other IQ measures.

Adult (Age 48) Outcomes. We examined the effects of the family-contextual and individual/personal variables assessed at age 8 on three domains of adult outcomes at age 48: aggression, intellectual/educational achievement, and occupational status.

AGGRESSION. Aggression was evaluated with four measures: (a) Severe physical aggression was assessed through participants' self-reports of how often in the last year they engaged in each of four behaviors (e.g., choked, slapped or kicked, punched or beat someone; $1=$ never to $4=\mathrm{alot})(\alpha=.66)$. (b) Aggressive personality was measured by taking the sum of scales 4, 9 , and F from the Minnesota Multiphasic Personality Inventory (MMPI; Hathaway \& McKinley, 1940). In earlier studies by our group (e.g., Huesmann et al., 1984; Huesmann, Lefkowitz, \& Eron, 1978), the summed T-scores of these three scales reflected a reliable and valid measure of aggressive behavior. For these scales, participants read 143 statements and indicated whether each was true (1) or false (o) in describing themselves. T-scores were computed for each scale, and a total score for each respondent was computed from the sum of the three T-scores $(\alpha=.78)$. (c) Aggression toward spouse was measured by nine items from the Home Violence Questionnaire (Straus, Giles, \& Steinmetz, 1979). Participants who were currently married or had recently lived with a partner or spouse indicated the frequency with which they directed threatening (e.g., with a knife or gun) or physically aggressive (e.g., pushed or shoved, beat up) acts towards their partner in the last 12 months. They made ratings on a 1o-point scale ranging from zero to "9 or more." The original participants self-reported on their behavior toward their spouses, and spouses reported on the participant's behaviors toward them ( $\alpha=.72$ for self-reports and .9o for other reports). For the present analyses, a composite score was calculated to reflect the average of the participants' and spouses' (if available) reports. (d) Parent hitting child as a form of punishment was measured. Original participants indicated the frequency with which they engaged in various forms of purishment while their children (generally the oldest and youngest) were growing up. Five of the punishments reflected hitting (e.g., slap in face, spank or beat with a stick or belt) with a 4 -point response scale $(1=$ never, $2=$ seldom, $3=$ sometimes, $4=$ often). Using the same measure, spouses and up to two children over age 19 rated the degree to which the original participant used hitting as a form of punishment. Coefficient alphas across reporters (self, children, spouse) were above .70. A composite score was calculated to reflect the average punishment-hitting score across up to six potential reports.

INTELLECTUAL/EDUCATIONAL ACHIEVEMENT. Intellectual/educational achievement was assessed using three measures: (a) The participant's standard scores were compiled from the Wide Range Achievement Test-Revised (Jastak \& Jastak, 1978) arithmetic and verbal sections (reading test for personal interviews, spelling test for phone interviews; arithmetic in personal interviews only); (b) Years of education ranged from $1=$ did not complete high school to $7=$ doctoral/law degree; (c) Perceived cognitive competence was assessed using two self-report items (Harter, 1985) presented as pairs of opposing descriptions (e.g., "Some adults feel they are intelligent, BUT other adults question whether they are intelligent"; $\alpha=.70$ ). Participants select which description applies best to them, and then they indicate whether the description is "sort of true" or "really true" for them.

oCCUPATIONAL SUCCEss. Occupational success was estimated using prestige codes following Stevens and Hoisington (1987). Prestige codes are provided for 889 specific occupations within 13 occupational categories (e.g., executive, administrative, and managerial; professional specialty; technicians; sales; protective service; mechanics/repairers; machine 
operators and inspectors). Higher codes indicate greater prestige. The codes range from 153 (ushers) to 810 (physicians). Two raters coded the participants' occupations. On a subsample of 162 occupations coded by each rater, the correlation between their assigned prestige codes was $r=.81$.

\section{RESULTS}

\section{Overview of Analyses}

We first examine gender differences in middle childhood family-contextual and personal factors and the age 48 outcome variables. Next, we examine the predictive effects of the middle childhood contextual and personal factors on each of the three domains of age- 48 outcomes (aggression, intellectual/educational achievement, occupational success). For each domain, we present: (a) correlations of the age- 8 personal factor with the associated measures of the same domain of behaviors at age 48 , as an indication of the degree of continuity in the behavior over 40 years; (b) contemporaneous correlations between the age- 8 family-contextual factors and the age- 8 personal variable; (c) correlations of the middle childhood family-contextual and personal factors with each age- 48 measure; and (d) a multiple-group (males and females) structural model using AMOS (Arbuckle, 1997) to examine the effects of middle childhood family-contextual and personal factors in predicting the age- 48 outcome construct. In all analyses the log transformation of peer-nominated aggression (age 8) and self-reported severe aggression (age 48 ) were used because their distributions were highly skewed.

\section{Gender Differences in Middle Childhood Factors and Age-48 Outcomes}

There are no gender differences in the middle childhood family background (SES) measures (i.e., father's occupation, parental education, and value of housing). There are gender differences in two of the middle childhood negative family interaction measures: (a) parents reported higher levels of rejection (dissatisfaction) toward boys than toward girls, $t(705)=$ $4.32, p<.01$; and (b) parents reported more endorsement of hitting as a form of punishment toward their boys than toward their girls, $t(697)=$ $1.98, p<.05$. At age 8 , boys $(M=16.0, S D=15.7)$ are rated as more aggressive by their classroom peers than are girls $(M=9.4, S D=11.0), t(854)=$ $7.74, p<.01$, but there are no gender differences in peer-nominated popularity or IQ.

At age 48 , we find no gender differences on the measures of aggression toward spouse or aggressive personality. However, males score higher than females on severe physical aggression, $t(481)=2.80, p<.01$. Females score
TABLE 4.1. Contemporaneous Correlations of the Age-8 Family-Contextual Factors with the Age-8 Personal Variables

\begin{tabular}{|c|c|c|c|c|c|c|}
\hline \multirow[b]{3}{*}{ Age-8 Factors } & \multicolumn{6}{|c|}{ Age-8 Personal Variables } \\
\hline & \multicolumn{3}{|c|}{ Males } & \multicolumn{3}{|c|}{ Females } \\
\hline & $\begin{array}{l}\log \\
\text { Agg }\end{array}$ & $I Q$ & Pop & $\begin{array}{l}\log \\
A g g\end{array}$ & $I Q$ & Pop \\
\hline \multicolumn{7}{|l|}{ Family background (SES) } \\
\hline Father's occupation & & $.10^{+}$ & & & $.13^{+}$ & \\
\hline Parent education & & $3 \mathrm{I}^{* *}$ & $.24^{* *}$ & $-.14^{* *}$ & $.35^{* *}$ & $.22^{*}$ \\
\hline Value of housing & $-.17^{* *}$ & $.36^{* *}$ & $.22^{* *}$ & $-.13^{*}$ & $.29^{* *}$ & $.17^{* *}$ \\
\hline \multicolumn{7}{|l|}{ Negative family interaction } \\
\hline $\begin{array}{l}\text { Rejection } \\
\text { Punishment (hitting) of } \\
\text { child }\end{array}$ & $.23^{* *}$ & $-.18^{* *}$ & $\begin{array}{l}-.14^{* *} \\
-.11^{*}\end{array}$ & $\begin{array}{l}.33^{* *} \\
.15^{* *}\end{array}$ & $-.14^{*}$ & $-30^{* *}$ \\
\hline Parental disharmony & & & & $.17^{* *}$ & & $-.11^{+}$ \\
\hline
\end{tabular}

Note: Log Agg log-transformed peer-nominated aggression; Pop = peer-nominated popularity. Non-significant correlations are not shown.

${ }^{+} p<.10{ }^{*} p<.05 .{ }^{* *} p<.01$.

higher than males on the WRAT-R verbal test, $t(519)=3.45, p<$. or, but males score higher than females on the WRAT-R arithmetic test, $t(279)=$ $2.10, p<.05$. There are no significant gender differences in years of education attained by age 48 or on self-perceptions of cognitive competence. There is no significant gender difference in occupational prestige.

\section{Predicting Age-48 Aggression from the Middle Childhood Factors}

There is some continuity of aggression over 40 years despite the very different methods of measuring aggressive behavior at those time points. For males, age- 8 peer-nominated aggression is related positively to three indices of age-48 aggression: aggressive personality $(r=.32, p<$ $.01)$, severe physical aggression $(r=.15, p<.05)$, and aggression toward spouse $(r=.14, p<.01)$, and to a composite aggression variable created by summing the subject's $z$-scores for each aggression measure $(r=.28, p<$ .01). For females, age- 8 peer-nominated aggression is related positively to punishment (hitting) of child $(r=.22, p<.01)$, aggressive personality $(r=$ $.14, p<.05)$, and the composite aggression measure $(r=.19, p<.01)$.

Table 4.1 shows the contemporaneous correlations of the middle childhood family-contextual variables with the middle childhood personal variables. The relations among middle childhood family-contextual variables and aggression are generally modest in magnitude; the strongest indicate that higher levels of parental rejection are related to higher levels of peernominated aggression for both genders. 
Table 4.2 shows the correlations of the middle childhood aggression and family-contextual variables with the age- 48 aggression measures. Several of these are significant but are generally modest in magnitude. Specifically, for males, higher levels of family SES background variables and lower levels of negative family interaction during middle childhood are related to lower levels of adult aggression (most consistently for the composite aggression score and for aggressive personality). For females, fewer correlations are significant, but three of the middle childhood family-contextual variables (lower father's occupation and parental education, and higher parental disharmony) predict how much they use hitting as a form of punishing their children.

Next, we computed a multiple-group structural model (males and females) of the relations of the middle childhood contextual variables and aggression to adult aggression. We constrained the measurement parameters for the family background (the construct is labeled "SES" on the figures) indicators and for the negative family interaction indicators to be equal across gender, but we allowed the measurement parameters to vary across gender for adult aggression because adult aggression appears to comprise different combinations of the age- 48 aggression variables for males and females. We allowed the paths among the latent variables to vary by gender. The fit of the multiple-group model is fair (RMSEA $=.044$, GFI = .93), indicating that the measurement of the constructs and the relations among them - albeit at different levels of magnitude for each gender approximately describe the obtained pattern of correlations. Figure 4.1 shows that for males, lower middle childhood SES and higher negative family interaction are related directly to higher age- 48 aggression, and the effect of negative family interaction on age- 48 aggression also is mediated by age- 8 aggression. Figure 4.1 also shows that for females, the effect of age-8 aggression on age- 48 aggression is not significant: Only lower middle childhood SES significantly predicts higher age- 48 aggression for females. ${ }^{2}$

\section{Predicting Age-48 Intellectual/Educational Achievement from the Middle Childhood Factors}

As was shown in Table 4.1, for both males and females, higher levels of middle childhood family SES indices are related modestly to age-8 IQ, but only one negative family interaction measure, parental rejection, is related modestly to lower IQ scores. Table 4.3 shows the correlation of middle childhood IQ and family-contextual variations with the age- 48 achievement measures. As shown in Table 4.3, for both males and females, higher

2 A model in which the structural paths were constrained to be equal across genders provided a significantly poorer fit to the data as indicated by the chi-square difference test, $\chi^{2}(6)=$ $43.895, p<.000$.

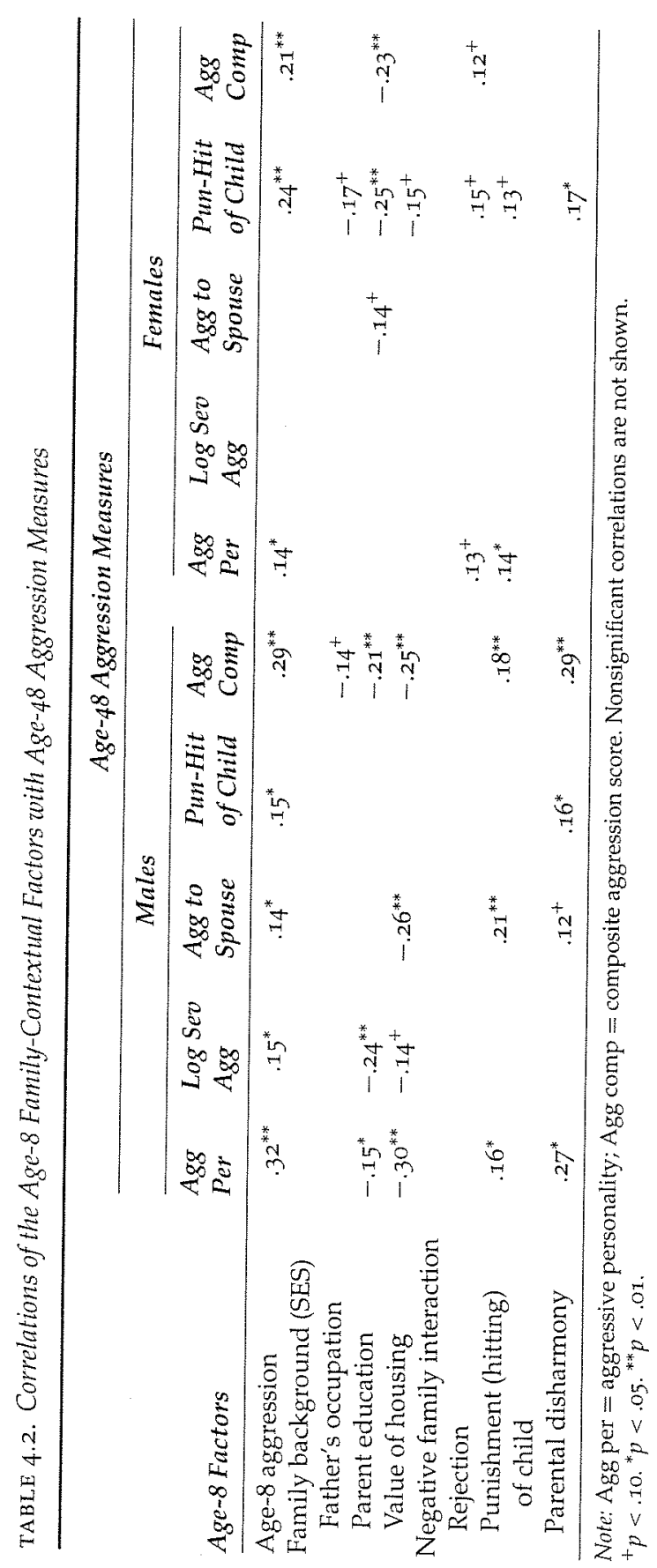




\section{Males}

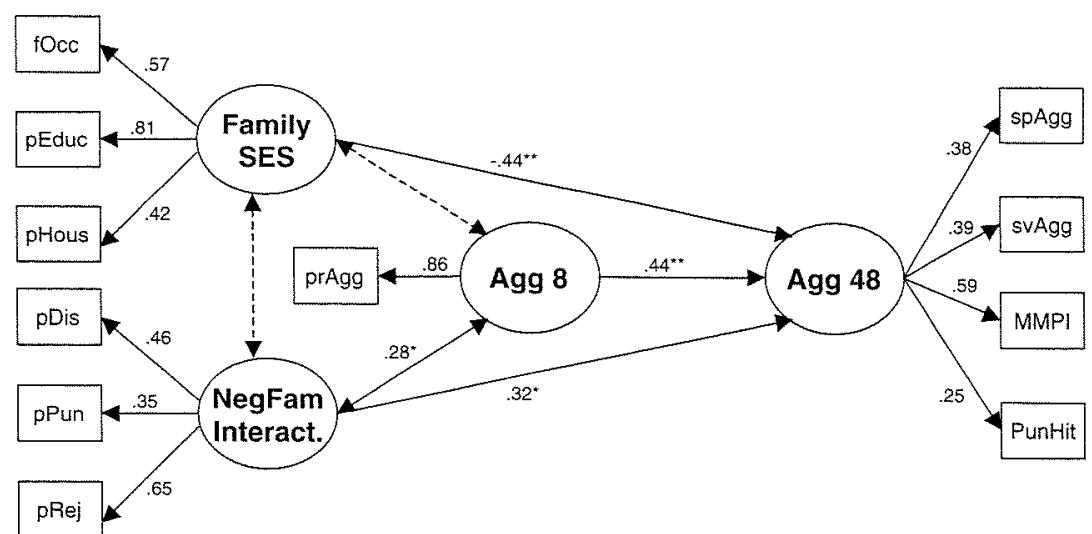

Females

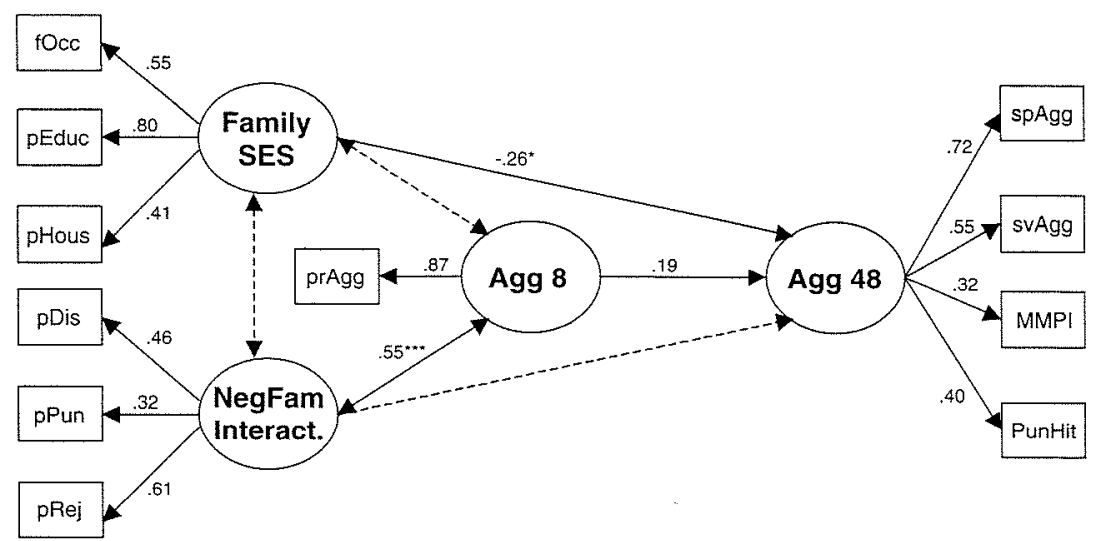

FIGURE 4.1. Structural models showing the effects of age- 8 family-contextual factors on aggressive behavior at ages 8 and 48 , with path coefficients for 234 males (top) and for 234 females (bottom) (multiple-group chi-square $=182.3, \mathrm{df}=93, \mathrm{RMSEA}=$ $.044, \mathrm{GFI}=.93$ ). Broken lines represent paths in the model for which the path coefficients are less than one standard error different from zero. FOcc = Father's occupation, 1960; pEduc $=$ Parents ${ }^{\prime}$ education, 1960 ; $\mathrm{pHous}=$ Value of family housing 1960; pDis = Parental disharmony, 1960; pPun = Physical punishment of child, 1960; pRej = Parental rejection of child, 1960; prAgg = Peer-nominated aggression (logged), 1960; spAgg = Subject/spouse reports of subjects' aggression to spouse, 2000; svAgg = Subject's severe physical aggression (logged), 2000; MMPI = Sum of F, 4, 9 scales of MMPI, 200o; PunHit = Subject/spouse/child reports of subjects' use of physical punishment, 2000

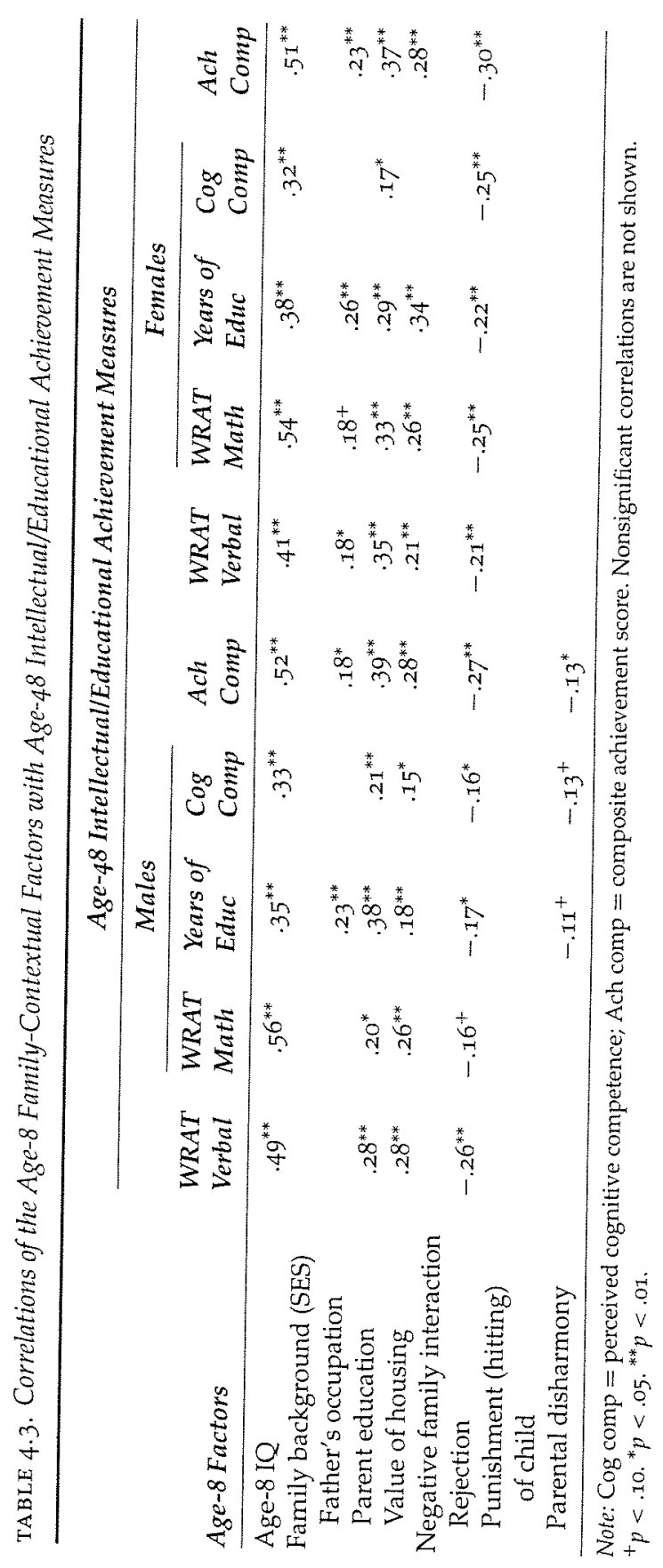

${ }^{*} p<.05,{ }^{* *} p<.01,{ }^{* *} p<.001$. 
levels of family SES in middle childhood are associated with higher educational and intellectual achievement at age 48 . Of the three family interaction variables, only parental rejection in middle childhood is associated consistently with low achievement at age 48 .

A multiple-group structural model (males and females) of the relations of the middle childhood family-contextual variables and age-8 IQ to adult intellectual/educational achievement is shown in Figure 4.2. We constrained the measurement parameters for the family background indicators (labeled in the figures as "SES") and for the negative family interaction indicators to be equal across gender and to be equal to the measurement parameters for these constructs found in the earlier aggression models. We also constrained the measurement parameters for the age48 intellectual/educational achievement construct to be equal across genders. We included bidirectional relations of the middle childhood familycontextual factors and middle childhood IQ. The fit of the multiple-group model is adequate (RMSEA $=.037, \mathrm{GFI}=.94$ ) and the relations among the variables are similar for males and females. ${ }^{3}$ As expected, for both males and females, higher levels of age- 8 IQ are related moderately to age- 48 intellectual/educational achievement. In addition, higher levels of middle childhood SES and lower levels of negative family interaction are directly related to higher levels of intellectual/educational achievement at age 48 .

\section{Predicting Age- 48 Occupational Prestige from the Middle} Childhood Factors

Although there is no corresponding personal factor at age 8 for age- 48 occupational prestige, as Table 4.4 shows, the correlations of the age- 8 aggression, popularity, and IQ with age- 48 occupational prestige are significant for both males and females. As expected childhood aggression predicts less occupational success while greater popularity and higher IQs predict more success. Parental rejection of the child at age 8 is also inversely related to the child's eventual occupational prestige 40 years later for both genders. However, the family background SES variables relate to the child's eventual occupational prestige more strongly for males than for females.

To examine the combined effect of these middle childhood variables in predicting occupational success later in life, we computed a multiplegroup model (males and females) of the relations of the middle childhood family-contextual variables and age-8 IQ, popularity, and aggression to adult occupational prestige. We computed composite family background

3 A model in which the structural paths were not constrained to be equal across genders provided no better fit to the data; $\chi^{2}(5)=4.9, p=.432$.

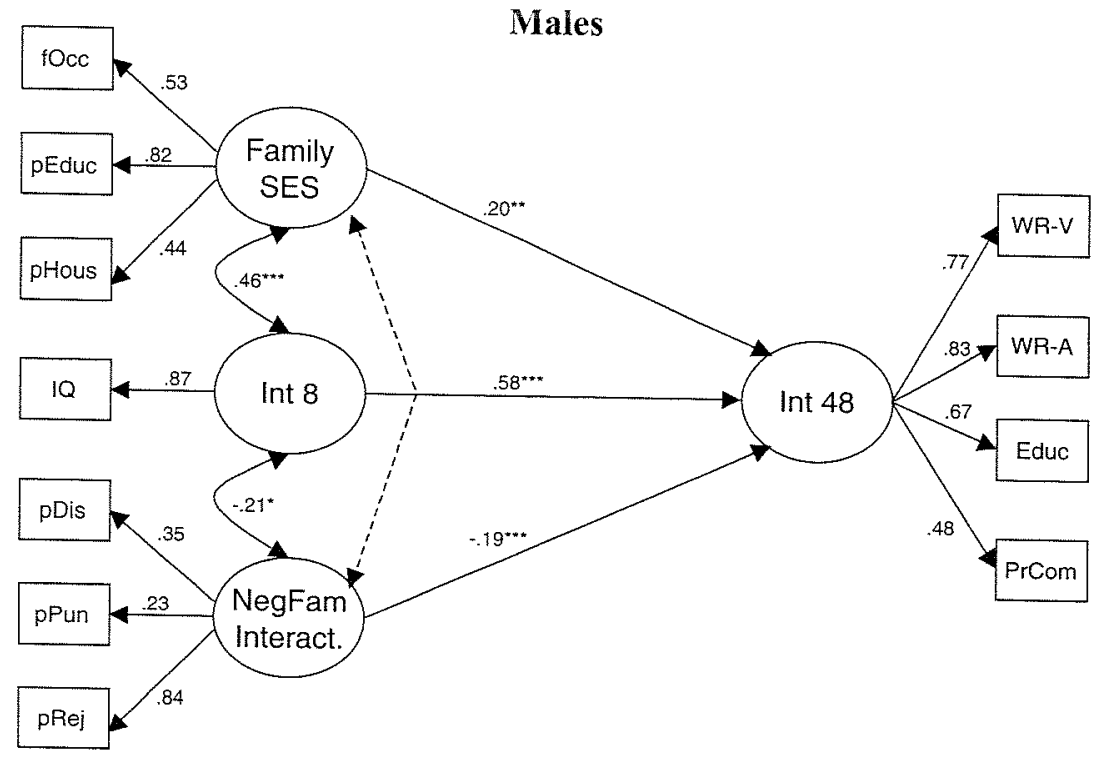

Females

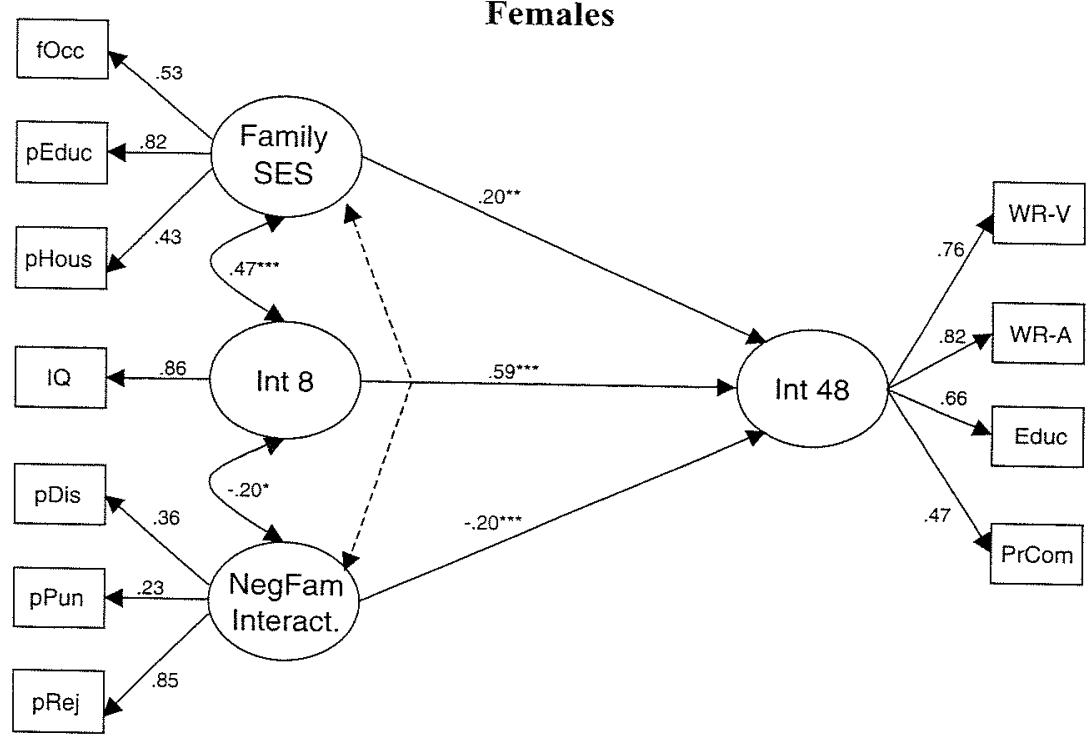

FIGURE 4.2. Structural models showing the effects of age-8 family-contextual factors on intellectual ability at ages 8 and 48 , with path coefficients for 234 males (top) and for 234 females (bottom) (multiple-group chi-square $=165.5, \mathrm{df}=101, \mathrm{RMSEA}=.037, \mathrm{GFI}=.94$ ). Broken lines represent paths in the model for which the path coefficients are less than one standard error different from zero. For variables not duplicating Figure 4.x: IO = Subject's IQ score on Short Form Test of Mental Maturity 1960: WR-V = Verbal score on Wide Achievement Test (WRAT), 2000; WR-A = Arithmetic score on WRAT, 2000; Educ = Level of educational attainment by $2000 ; \mathrm{PrCom}=$ Perceived cognitive competence.

${ }^{*} p<.05,{ }^{* *} p<.01,{ }^{* * *} p<.001$. 
TABLE 4.4. Correlations of Age-8 Family-Contextual Factors and Personal Variables with Age-48 Occupational Prestige

\begin{tabular}{lcc}
\hline & \multicolumn{2}{l}{ Age-48 Occupational Prestige } \\
\cline { 2 - 3 } Personal Variables & Males & Females \\
\hline Family background (SES) & & \\
Father's occupation & $.22^{* *}$ & $.16^{+}$ \\
Parent education & $.25^{* *}$ & $.14^{+}$ \\
$\quad$ Value of housing & $.14^{*}$ & \\
Negative family interaction & & $-.21^{* *}$ \\
Rejection & $-.20^{* *}$ & \\
Punishment (hitting) of child & & $.15^{*}$ \\
Parental disharmony & & $.32^{* *}$ \\
Personal variables & $-.26^{* *}$ & $.26^{* *}$ \\
Aggression & $.28^{* *}$ & \\
Popularity & & \\
IQ &
\end{tabular}

Note: Nonsignificant correlations are not shown. ${ }^{+} p<.10{ }^{*} p<.05 .{ }^{* *} p<.01$.

(labeled in the figures as "SES") and negative family interaction variables by summing the $z$-scores for the variables comprising those constructs. For this model, we conceptualized SES, negative family interaction, and age-8 IQ as intercorrelated exogenous factors with age-8 popularity and aggression as endogenous mediating factors. We constrained the error parameters of the endogenous variables to be equal across genders. A fair fit is obtained (RMSEA $=.058, \mathrm{GFI}=.987$ ), and a differential pattern of prediction emerges by gender. Figure 4.3 shows that for males, the effect of age- 8 IQ on adult occupational attainment is not direct - rather, IQ appears to affect occupation by influencing middle childhood aggression and popularity. That is, intellectual deficits are associated with higher aggression and lower popularity during middle childhood, which in turn are associated with lower levels of adult occupational status. Note also that middle childhood SES remains a significant direct predictor of adult occupational status for males. In contrast, for females (lower panel of Figure 4.3), only higher middle childhood IQ significantly predicts higher age-48 occupational prestige. No other middle childhood variables in the model predict occupational prestige for females at a statistically significant level. ${ }^{4}$

4 A model in which the structural paths were constrained to be equal across genders provided a significantly poorer fit to the data as indicated by the chi-square difference test, $\chi^{2}(13)=$ $30.173, p<.01$.
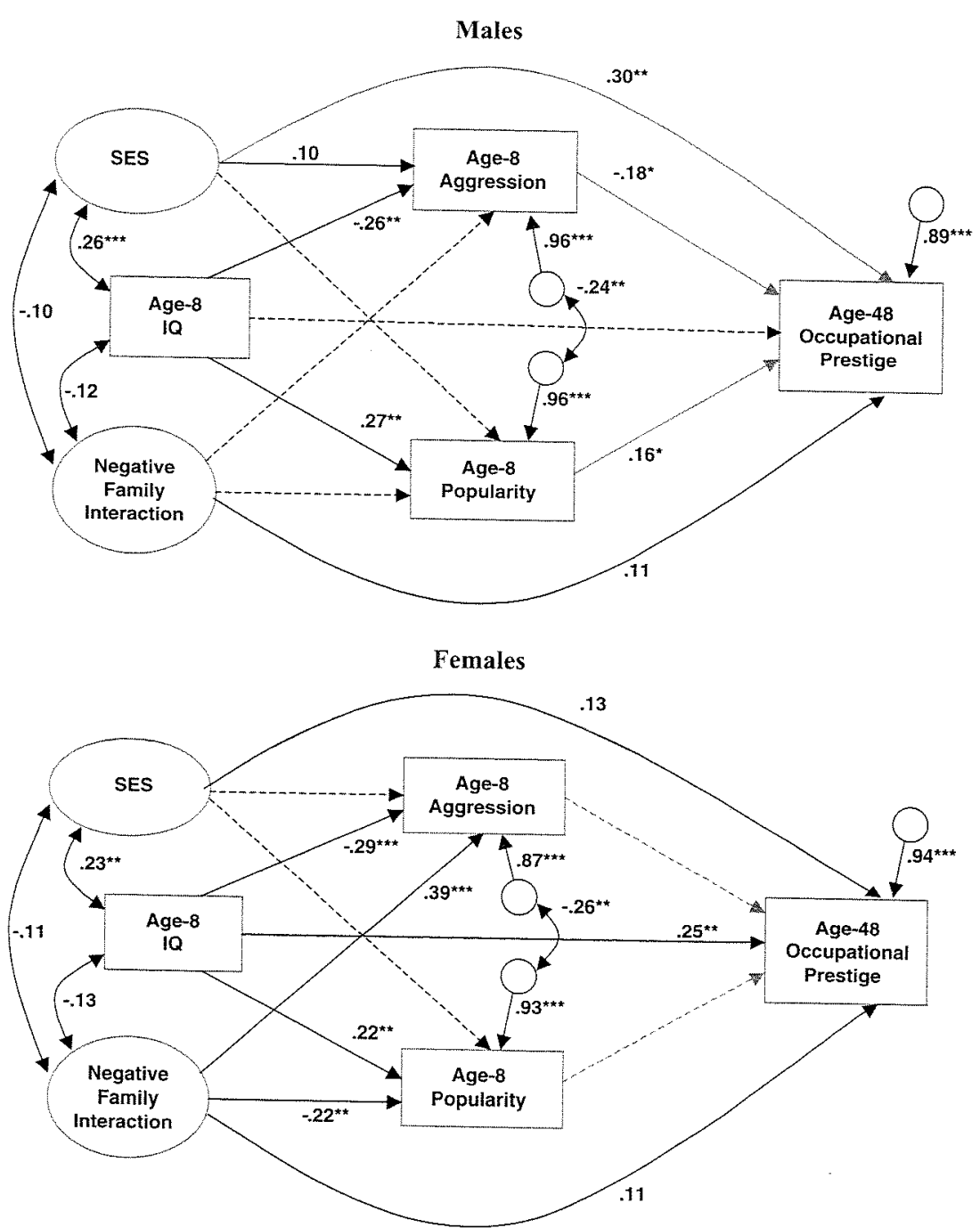

FIGURE $4 \cdot 3$. Structural models showing the mediated effects of age- 8 family-contextual factors and IQ through age- 8 aggression and popularity on occupational prestige at age 48 , with path coefficients for 160 males (top) and for 139 females (bottom) (multiple-group ahi- 48, with $11.928, \mathrm{df}=6, \mathrm{RMSEA}=.058, \mathrm{GFI}=.987$ ) . The broken lines represent paths in the model for which the path coefficients are less than one standard error different from zero.

${ }^{*} p<.05,{ }^{* *} p<.01,{ }^{* * *} p<.001$. 
DISCUSSION

Family-contextual factors (i.e., family SES, negative family interactions) and personal variables (i.e., aggression, $I Q$, popularity) during middle childhood predicted adult outcomes (i.e., aggression, intellectual achievement, and occupational prestige) in important ways. Higher family SES during middle childhood predicted lower adult aggression and higher adult intellectual achievement for both genders and higher adult occupational achievement for males, even after controlling for middle childhood family interaction factors and personal variables. Negative family interaction variables in middle childhood predicted lower levels of adult aggression and intellectual achievement for both males and females as well but did not have a significant effect on adult occupational prestige independently of the child's IQ and the family's SES (despite the significant correlation of childhood rejection with lower occupational success). Although higher age-8 IQ predicted adult occupational success for both males and females, the effect was direct for females and mediated through lower aggression and higher popularity for males. These results add to the growing body of knowledge on the course of individual development, and raise some provocative questions concerning mechanisms affecting continuity and change from middle childhood to adulthood.

\section{Middle Childhood Contextual and Personal Predictors \\ of Adult Aggression}

Consistent with prior research on the continuity of individuals' aggression over time (e.g., Farrington, 1990; Loeber \& Dishion, 1983), we observed substantial (for a 40-year lag) and significant correlations for both males and females between age- 8 peer-nominated aggression and the age- 48 aggression composite score. However, notable gender differences were found in the correlations from child aggression to specific kinds of adult aggression. For females, the highest correlation was to "hitting your child" and the next highest was to aggressive personality. For males, the highest correlation was to aggressive personality. For males but not for females, there were correlations to interpersonal physical aggression and aggression "against your spouse." These patterns of longitudinal relations are consistent with the principle that each gender displays aggression consistent with gender roles for the culture.

Striking gender differences were also evident in the extent to which middle childhood factors predicted adult aggression. First, the continuity coefficient for aggression (i.e., age- 8 aggression to age- 48 aggression), when these other childhood factors were considered was considerably larger for males than for females. Second, the influence of childhood family-contextual factors differed by gender. For males, negative family interactions during middle childhood exerted an effect on aggression 40 years later even after accounting for its effects on aggression during middle childhood. However, for females, the deleterious effects of negative family interactions on aggression occurred only during middle childhood.

Although biological factors obviously play an important role in gender differences in aggression, these results suggest that differential socialization in middle childhood is also important. Boys, more than girls, are socialized to display a certain degree of overt "tough" and masculine aggressive behavior; girls with aggressive tendencies must therefore find more socially acceptable ways to express aggression. Thus, we have observed differences over time in males' tendency to display more public forms of aggression, with females limiting their aggression to more private situations such as child rearing (Eron \& Huesmann, 1989). Furthermore, because females' aggression after middle childhood is likely to be more indirect and less public, individual differences in parental responses to overt "bad" behavior reflected by the Negative Family Interaction variables are less likely to be predictive of individual differences in females' subsequent aggressive
behavior.

\section{Middle Childhood Contextual and Personal Predictors of Adult Intellectual Achievement}

The relations between middle childhood IQ and middle adulthood achievement demonstrated moderate continuity across a variety of specific adult measures. These results are consistent with research on the shortterm and long-term stability of intellectual and educational achievement (e.g., Chen, Lee, \& Stevenson, 1996; Zax, Cowen, Beach, \& Rappaport,
1972).

Longitudinal structural models predicting adult intellectual achievement from middle childhood IQ as well as family-contextual variables were more consistent across gender than were models of aggression. Both family SES and negative family interactions in middle childhood exerted significant direct effects on adult achievement, over and above the best prediction from age- $8 \mathrm{IQ}$. This is a very important finding. Much of the contemporary literature on achievement outcomes, particularly from childhood into young adulthood, emphasizes the crucial role of family factors such as child rearing variables (e.g., discipline, warmth), parent characteristics (e.g., achievement expectations), and SES in the emergence and maintenance of academic success (Davis-Kean, 2003; Duncan, Brooks-Gunn, \& Klebanov, 1994; Mistry, Vandewater, Huston, \& McLoyd, 2002). The results of the current investigation underscore the importance of those factors by demonstrating their continuing influence into middle adulthood. 


\section{Middle Childhood Contextual and Personal Predictors of Adult} Occupational Prestige

Our findings with regard to the prediction of age- 48 occupational prestige present a complex picture of the ways in which family-contextual and personal factors differentially influence development by gender. Of the two middle childhood family-contextual predictors, only family SES had a direct long-term relation to age-48 occupational prestige in the structural models, and only for males. Higher childhood SES was associated with greater adulthood occupational prestige for males. Negative family interactions in middle childhood had no substantial effect for either males or females. For females, only age-8 IQ among the personal variables was related independently to adult occupational success. However, for males the effect of age-8 IQ on adult occupational success was mediated almost entirely by IQ's relations to age- 8 aggression (inverse) and age-8 popularity (direct). For males, occupational prestige in middle adulthood appears to be more the product of the possible effect that lower IQ has on depressing social competence than on any direct effect of IQ on occupational prestige. From a social capital perspective (Eccles, Templeton, Barber, \& Stone, 2003; Parke, 2004), it is possible that higher SES parents provided tangible opportunities for their boys' vocational development (e.g., business opportunities, connections to jobs in the community through their own personal networks). Perhaps more socially skilled boys were better able to take advantage of these opportunities. Given the period during which the Columbia County cohort was growing up (i.e., in the 195 os and 1960s), societal expectations for occupational attainment might have been less critical for girls, so those opportunities might not have been provided for them. For girls to achieve higher occupational attainment later in life, their intellectual abilities might have been more important.

\section{Implications}

Our findings provide an initial look at the ways in which middle childhood family-contextual and personal factors continue to exert influence on important domains of functioning into middle adulthood. Our analyses highlight the predictive value of middle childhood variables for explaining aggression, intellectual competence, and occupational prestige over 40 years. However, the results also raise a critical overarching question: What processes or mechanisms account for continuity or discontinuity over time?

Contextual factors are thought to influence the development of attitudes and beliefs that in turn lead to the emergence and continuity/discontinuity of behavior (e.g., Bandura, 1986; Huesmann, 1998; Wigfield \& Eccles, 2000). Cognitive processing models posit that behavior is maintained over time through the formation and application of attitudes and beliefs that emerge initially through observational and direct learning experiences to which the child is exposed across multiple contexts; cognitions then crystallize and are strengthened through adolescence and adulthood. For example, males who come to believe that aggression is acceptable (perhaps through cumulative exposure to aggressive models in the home, media, etc.) should be more likely to behave aggressively in the long run, which will interfere with social relations and make success in life more difficult. Females who value educational attainment (perhaps through exposure to higher SES family contexts where cognitively stimulating resources are available) should show higher achievement in childhood and be more likely to experience academic and vocational success. In other words, it may be that females develop their motivation to achieve through their positive experiences with schooling, whereas males might develop similar motivation through positive social interactions. Thus, higher IQ for females leads to reinforcement of an achievement-oriented self-concept through academic successes, whereas social facility for males leads to reinforcement of an achievement-oriented self-concept through social
success.

In sum, our analyses have identified middle childhood familycontextual factors that predict adult outcomes. However, we recognize that this is only a first step toward understanding the specific processes by which these factors operate to affect adult development, and how these processes might operate differentially by gender.

This project was supported by funding from the National Institute of Child Health and Human Development (Ro1 HD 036056-06). We acknowledge the assistance of David Slegers in the preparation of this manuscript. Address all correspondence to L. Rowell Huesmann, Ph.D., Research Center for Group Dynamics, 5035 ISR, University of Michigan, 426 Thompson Street, Ann Arbor, MI 48106. Email: huesmann@umich.edu.

\section{References}

Arbuckle, J. L. (1997). AMOS users' guide version 3.6. Chicago: SmallWaters Corporation.

Bandura, A. (1986). Social foundations of thought and action: A social cognitive theory. Englewood Cliffs, NJ: Prentice-Hall

Chen, C., Lee, S., \& Stevenson, H. W. (1996). Long-term prediction of academic achievement of American, Chinese, and Japanese adolescents. Journal of Educational Psychology, 88, 750-759.

Coie, J. D., \& Dodge, K. A. (1983). Continuities and changes in children's social status: A five-year longitudinal study. Merrill-Palmer Quarterly, 29, 261-282.

Guilford.
u. \& Davies, P. T. (1994). Children and marital conflict. New York: 
Davis-Kean, P. E. (2003, April). The influence of parent education on child outcomes: The mediating role of parents' beliefs and behaviors. Paper presented at the biennial meeting of the Society for Research in Child Development, Tampa, FL.

Duncan, G. J., Brooks-Gunn, J., \& Klebanov, P. K. (1994). Economic deprivation and early childhood development. Child Development, 65, 296-318.

Eccles, J. S. (1994). Understanding women's educational and occupational choices: Applying the Eccles et al. model of achievement-related choices. Psychology of Women Quarterly, 18, 585-609.

Eccles, J., Templeton, J., Barber, B., \& Stone, M. (2003). Adolescence and emerging adulthood: The critical passage ways to adulthood. In M. H. Bornstein, L. Davidson, C. L. M. Keyes, \& K. A. Moore (Eds.), Well-Being: Positive development across the life course (pp. 383-406). Mahwah, NJ: Lawrence Erlbaum Associates.

Erikson, E. H. (1963). Childhood and society (2nd ed). New York: W. W. Norton \& Company.

Eron, L. D., \& Huesmann, L. R. (1989). The genesis of gender differences in aggression. In M. A. Luscz \& T. Nettlebeck (Eds.), Psychological development: Perspectives across the life span (pp. 55-67). Amsterdam: Elsevier.

Eron, L. D., Walder, L. O., \& Lefkowitz, M. M. (1971). Learning of aggression in children. Boston: Little, Brown.

Farrington, D. P. (1990) Childhood aggression and adult violence: Early precursors and later life outcomes. In D. J. Pepler \& K. H. Rubin (Eds.), The development of childhood aggression. Hillsdale, NJ: Erlbaum.

Freud, S. (1961). The ego and the id. In J. Strachey (Ed. \& Trans.), The standard edition of the complete psychological works of Sigmund Freud (Vol. 19, pp. 3-66). London: Hogarth Press. (Original work published 1923.)

Harter, S. (1985). Manual for the Self-Perception Profile. Denver, CO: University of Denver.

Hathaway, S. R., \& McKinley, J. C. (1940). A multiphasic personality schedule (Minnesota): I. Construction of the schedule. Journal of Psychology, 10, $249-254$.

Huesmann, L. R. (1998). The role of social information processing and cognitive schema in the acquisition and maintenance of habitual aggressive behavior. In R. G. Geen \& E. Donnerstein (Eds.), Human aggression: Theories, research, and implications for social policy (pp. 73-109). San Diego, CA: Academic Press.

Huesmann, L. R. (2001). Gender differences in the continuity of aggression from childhood to adulthood: Evidence from some recent longitudinal studies. Paper presented at the 2001 G. Stanley Hall Symposium on Gender and Aggression. Williams College, Williams, Massachusetts.

Huesmann, L. R., Dubow, E. F., Eron, L. D., Boxer, P., Slegers, D., \& Miller, L. S. (2002, November). Continuity and discontinuity of aggressive behaviors across three generations. Paper presented at the meeting of the Society for Life History Research on Psychopathology, New York.

Huesmann, L. R., \& Eron, L. D. (1986). Television and the aggressive child: A crossnational comparison. Hillsdale, NJ: Erlbaum.

Huesmann, L. R., Eron, L. D., Lefkowitz, M. M., \& Walder, L. O. (1984). Stability of aggression over time and generations. Developmental Psychology, 20, 1120II34.
Huesmann, L. R., \& Guerra, N. G. (1997). Children's normative beliefs about aggression and aggressive behavior. Journal of Personality and Social Psychology, 72, 408419.

Huesmann, L. R., Lefkowitz, M. M., \& Eron, L. D. (1978). The sum of MMPI scales F 4 , and 9 as a measure of aggression. Journal of Consulting and Clinical Psychology 46, $1071-1078$.

Jacobs, J. E., Bleeker, M. M., \& Constantino, M. (2003). The self-system during childhood and adolescence: Development, influences, and implications. Joumal of Psychotherapy Integration, 13, 33-65.

Jastak, J. F., \& Jastak, S. (1978). Wide Range Achievement Test-Revised. Wilmington, DE: Jastak Associates.

Jimerson, S., Egeland, B., Sroufe, L. A., \& Carlson, B. (2000). A prospective longitudinal study of high school dropouts examining multiple predictors across development. Journal of School Psychology, 38, 525-549.

Kokko, K., \& Pulkkinen, L. (2000). Aggression in childhood and long-term unemployment in adulthood: A cycle of maladaptation and some protective factors. Developmental Psychology, 36, 463-472.

Lefkowitz, M. M., Eron, L. D., Walder, L. O., \& Huesmann, L. R. (1973). Preference for televised contact sports as related to sex differences in aggression. Developmental Psychology, 9, 417-420.

Lefkowitz, M. M., Eron, L. D., Walder, L. O., \& Huesmann, L. R. (1977). Growing up to be violent. New York: Pergamon.

Leventhal, T., \& Brooks-Gunn, J. (2000). The neighborhoods they live in: The effects of neighborhood residence upon child and adolescent outcomes. Psychological Bulletin, 126, 309-337.

Loeber, R., \& Dishion, T. (1983). Early predictors of male delinquency: A review. Psychological Bulletin, 94, 68-99.

McHale, S. M., Dariotis, J. K., \& Kauh, T. J. (2003). Social development and social relationships in middle childhood. In R. M. Lerner \& M. A. Easterbrooks (Eds.) Handbook of psychology: Vol. 6, Developmental psychology (pp. 241-265). New York: John Wiley \& Sons, Inc.

Mistry, R. S., Vandewater, E. A., Huston, A. C., \& McLoyd, V. C. (2002). Economic well-being and children's social adjustment: The role of family process in an ethnically diverse low-income sample. Child Development, 73, 935-951.

Parke, R. D. (2004). Development in the family. Annual Review of Psychology, 55, 365-399.

Patterson, G. R. (1982). Coercive family process. Eugene, OR: Castalia.

Phelps, E., Furstenberg, F. F., \& Colby, A. (2002). Looking at lives: American longitudinal studies of the $20^{\text {th }}$ century. New York: Russell Sage Foundation.

Piaget, J. (1965). The child's conception of the world. Totowa, NJ: Littlefield, Adams.

Pulkkinen, L., \& Caspi, A. (Eds.) (2002). Paths to successful development: Personality in the life course. Cambridge, UK: Cambridge University Press.

Pulkkinen, L., Nygren, H., \& Kokko, K. (2002). Successful development: Childhood antecedents of adaptive psychosocial functioning in adulthood. Journal of Adult Development, $9,251-265$.

Stevens, G., \& Hoisington, E. (1987). Occupational prestige and the 1980 U.S. labor force. Social Science Research, 6, 74-105. 
Straus, M. A., Giles, R. J., \& Steinmetz, S. K. (1979). Behind closed doors: Violence in the American family. New York: Doubleday/Anchor.

Sullivan, E. T., Clark, W. W., \& Tiegs, E. W. (1957). California Short Form Test of Mental Maturity. Los Angeles: California Test Bureau.

Tolan, P. H., Gorman-Smith, D., \& Henry, D. B. (2003). The developmental ecology of urban males' youth violence. Developmental Psychology, 39, 274-291.

Warner, W. L., Meeker, M., \& Eells, K. (1960). Social class in America. New York: Harcourt.

Wigfield, A., \& Eccles, J. S. (2000). Expectancy-value theory of motivation. Contemporary Educational Psychology, 25, 68-8I.

Zax, M., Cowen, E. L., Beach, D. R., \& Rappaport, J. (1972). Longitudinal relationships among aptitude, achievement, and adjustment measures of school children. Journal of Genetic Psychology, 121, 145-154. 